\title{
Development of Blended Learning Model based on the Perceptions of Students at Higher Education Institutes in Oman
}

\author{
Virendra Gawande \\ Graduate School of eLearning, \\ Assumption University of Thailand
}

\begin{abstract}
In a traditional and rich society like in Oman, higher education offers several unique circumstances that suggest that, curriculum delivery using blended learning is a rational choice. The purpose of this study was to identify the factors affecting blended learning adoption and whether learning process was predictive in its adoption process at College of Applied Sciences (CAS) in Oman. The present study adopted quantitative approach that was aimed to examine the effect of students learning process and students learning style on blended learning. The findings of this study revealed that in particular, the Competitive and Facilitator style significantly mediated the relationship of User Acceptance of Technology and Blended Learning adoption. Further, the demographic factors like student's gender, age and computer experience does also significantly influenced the blended learning adoption. Blended learning design in the theoretical framework may enhance the interactions in learning environment and effective learning can be promoted through greater flexibility which may also allow the use of various learning styles.
\end{abstract}

\section{Keywords}

e-Learning, blended learning design, student learning styles, behavioural intention.

\section{INTRODUCTION}

Implementing information and communication technologies (ICTs) in learning and teaching activities has gained an immense interest among practitioners in higher education institutions (HEI) [19]. Today, ICT plays a major part in the pedagogical methodology which enables flexibility and reinforces interactivity to learning environment [34] in both inside and outside the classroom. The integration of ICT such as wikis, blogs, discussion forums, electronic mails, in learning and teaching in HEI highly changed the design of the curriculum and recently eLearning gained the significant part in teaching and learning experience for both teachers and students. In comparison to eLearning, the scholars predicted that the concept of blended learning, the combination of traditional face-to-face and technology mediated instruction would be the "new traditional model" or "new normal" in coming era of higher education course delivery [31], [17] \& [26].

Although the concept of blended learning is still an ambiguity in terms of its conceptual definition but the advantages of implementing such system offer various benefits to both students and teachers [10]. For instance, the studies conducted previously in developed countries reported that compared to traditional learning, blended format provides greater flexibility, motivation, idea sharing, interaction and better communication [15], [11] \& [10]. The studies conducted in developed countries concluded that online education is an important component of their long term strategy [4]. Despite these findings, still the results are inconsistent with regards to the student's acceptance and adoption level. Adoption is the key milestone that would ensure a productive use of a system, therefore understanding the user adoption of new technologies, can enhance the use of new technologies in education. However, such process is challenging, as it includes many factors that would influence the intention to use

\subsection{Higher Educational Institution and Blended learning in Oman}

The key accomplishments in the development the Omani Higher Education system was the establishment of Oman's first public university, the Sultan Qaboos University ( $S Q U$ ) in the year 1986. Later in 1994, the Ministry of Higher Education (MoHE) and the Ministry of Education (MoE) came into existence. During this time the six teachers' training colleges under the jurisdiction of the MoHE, were transformed into Colleges of Education, offering bachelor degrees in Education. In the year 2006, these six teachers' training colleges were converted into degree-granting Colleges of Applied Sciences (CAS). Oman adopted ICT later than many developed economies, confronting challenges of providing sufficient infrastructure for its widespread population on one hand, and a traditionalist people on the other. However, in the last five years have witnessed remarkable changes in the population, as wireless technologies came into stream, which enabled the Oman leapfrogged stages of ICT development through the advent of mobile devices.

Blended learning course system had given an opportunity to students in both distance-based and campus-based courses [33]. In Oman blended learning system is still in the developmental stage and there is ambiguity with respect to the development process of concepts of the delivery systems such as eLearning and blended learning [3]. In Oman, Colleges of Applied Sciences (CAS) started the Blended Learning in 2007, by using Blackboard as an LMS. One of the key objectives of CAS including includes "Leadership in technical and further education", by developing multimedia tools, and the rapid growth in online and distance education facilities with the flexibility of time and space.

Despite this the country is facing several unique circumstances such as increase in enrolment of students, lack of resources, inadequacy of faculty members, gender segregation and accommodation of student numbers. The current traditional system of HEI is not able to address these issues, and there is a need for some better system. 
Given that Ministry of Higher Education (MoHE), Oman has implemented blended learning in their institution for the first time, and they are in the initial stage of eLearning adoption cannot afford to fail in the eLearning implementation. It is recognized that unless the individual factors of teachers and students are considered potential of eLearning will not be fully utilised, thus lowering the return on investment [41]. Thus, present study aimed to take one aspect of this initiative, a new delivery in the Oman Higher Education i.e., Blackboard as a Learning Management System (LMS), and examine the various factors that influence the adoption of blended learning from user viewpoint, in this case students perspective. Further this study also examined whether learning style of students mediates the relationship between user acceptance and behavioural intention.

The main research question was: How does students' learning process affect the blended learning adoption at CAS in Oman?

\subsection{Theoretical background and Hypotheses}

There are several models have been identified adoption of technologies and to predict usage and behaviour. In order to predict the individual adoption of technologies, models like Theory of Reasoned Action (TRA), Technology Acceptance Model (TAM), Technology of Acceptance (TAM) [40], Theory of Planned Behaviour (TPB) and Unified Theory of Acceptance and Use of Technology (UTAUT) [40] had been widely used and validated tested by several researchers. The present study utilized UTAUT model which was proposed by Venkatesh [40], and ELAM proposed by Khan and Iyer (2009) for specifically eLearning acceptance [14]. In the present study context, researcher developed the model based on the ELAM and UTAUT. This is because, the existing ELAM was developed for eLearning and secondly, actual usage was removed as implementation of blended learning in Oman is at earlier stage. Further, the model also included demographic variables as a moderator to predict the adoption behaviour. The model consisted of four constructs namely effort expectancy, performance expectancy, facilitating condition and social influence which are direct determinants of behavioural intention. Demographic factors such as gender, age and computer experience was used as moderating variable while learning style of students was used as mediating variable. Figure 1, depicts the modified ELAM model adopted for blended learning at CAS.

\section{HYPOTHESES}

$\mathrm{H}_{1}$ : Performance expectancy of students has significant influence on blended learning adoption.

Performance expectancy is referred to as the degree to which people believed that their performance would improve by using this system [2]. Earlier research carried identified that there was no significant difference between genders in using blended learning adoption. In another research by Afarikumah and Achampong (2011), the perception of perceived usefulness was identified to be irrespective of student and level. In this study, perceived expectancy is said to be essential factor in blended learning adoption at CAS, Oman. In the present study, performance expectancy concerning to the degree of which students consider that their performance will be improved through blended learning adoption. Hence this hypothesis is formulated:

$\mathrm{H}_{2}$ : Effort Expectancy of students has significant influence on blended learning adoption.

Effort expectancy is referred to extent of ease-of-use associated with technology [35], [1] \& [32]. In the earlier study, effort expectancy is defined as the degree to which student believes that adoption of blended learning will have self-efficacy and ease-of-use. Previous studies has exhibited that effort expectancy is significant factor [7] \& [30]. Hence this hypothesis was formulated by relying on previous studies.

$\mathrm{H}_{3}$ : Social influence significantly influences blendedlearning adoption.

Social influence is defined as degree to which student considered that there is necessity to utilize the new system based on other's perceived belief [32]. Previous studies have confirmed that there is positive association between social influence and behaviour intention. Therefore, this hypothesis was formulated

$\mathrm{H}_{4}$ : Facilitating conditions of students significantly influences blended-learning adoption.

Facilitating condition denotes the extent to which student believes that technical and organizational infrastructure would support the usage of the new system [32]. As per the authors of the UTAUT model [40], facilitating condition has positive relationship with technology usage. Hence this hypothesis was generated based on the previous studies.

$H_{5}$ : The demographic variables of students significantly influences behavioural intention (blended learning)

The factors such as age, gender and the computer experience influence the blended learning adoption [22] \& [40]. The performance expectancy plays a major role with stronger intention among younger people. Perhaps the effects of effort expectancy and social influence were more salient for older people [40]. Further the aged people need more assistance than the young aged people in relation to the job context, known as facilitating conditions. The young age students enhance the performance in using the new technology than the older students. As per various researchers (e.g., [6], [40]) gender difference has moderating impact on the independent variable namely effort expectancy, social influence and performance expectancy as well as dependent variable like behaviour intention. $\mathrm{Li}$ and Kishore [20] have indicated that there is significant difference between gender group on effort expectancy and social influence. Thus, males were concerned about the performance while females were more conscious about the ease of use and others' issues. Further previous studies highlighted the eLearning attitudes have no significant impact on inexperienced users performances of eLearning [23]. Cavus et al. [9] has stated that there is no significant difference between age group and gender. By relying on the above studies, this hypothesis was formulated.

$\mathrm{H}_{6}$ : The relationship between user acceptance of technology and behavioural intention is mediated by the learning style of students.

Bostrom et al. [8] suggested that learning styles influences end-user training projects. The degree of correspondence highly influences learning performance, unlike learning style with respect to the behavioural intention (blended learning). The present study determines the factors of user acceptance of technology and learning style of the students which affect the blended learning at CAS in Oman. The study intended to identify the factors that affect blended learning process predictive of their adoption process at CAS in Oman. Hence this hypothesis was formulated

\section{RESEARCH METHODOLOGY}

The present empirical research was based on data collected from three academic departments of CAS i.e., Department of Information Technology, Department of Communication and Department of General Requirements. The participants were 
chosen using convenience sampling method, since this technique helps to select the participants who can best answer the research questions [28], rather than choosing the generalized population. The questionnaire was sent to 1020 students and only 841 participants responded with a response rate of $80 \%$. The data collection was done during the year 2012-2013.

\subsection{Research Instruments}

The research instrument adopted was structured questionnaire already been validated by previous studies empirically [40] with 39 items to measure the user acceptance [Behavioural intention (3 items), Facilitating conditions (9 items), Social influence (5 items), Performance expectancy (14 items), and Effort expectancy (8 items)] and Learning style of students adopted from Riechmann and Grasha, (1982). In addition, questionnaire also captured demographic information, age, gender, computer and internet experience. In this study 4 factors that would predict user acceptance were considered as independent variables, learning style of students was considered as mediator while behavioural intention as dependent variable. Further, demographic and computer usage was considered as a moderator. The questionnaire employed 5-point Likert Scale (Strongly disagree; Disagree; Neutral; Agree and Strongly agree) to grade the responses. The survey instrument was developed based on the previous UTAUT and other models. Initially, pilot study was conducted to test the reliability of questionnaire with academic experts. This helps to assess whether there are any ambiguities present in the questionnaire. Based on the suggestions, minor changes were made in the survey instrument. The items in the questionnaire were developed by relying on the research objectives. Large font sizes were used [13], along with more free spaces and prepared basically for a self-administration purpose.

\section{DATA ANALYSIS}

Collected data from the study sample were statistically computed using SPSS software (IBM Corp. Released 2012, version 21.0). Descriptive statistics was used to compute the average mean of the scores and standard deviations for all the employed variables. The reliability and validity of the questionnaire was tested using Cronbach's alpha. Factor analysis was used to identify dimensions and the underlying dimensions of user acceptance technology. To examine the impact of user acceptance on adoption of blended learning technology, multiple regression analysis was applied. To analyse the mediation, Sobel test was applied. The conditions for mediation tests was examined through four steps test such as: the total effect of $\mathrm{X}$ on $\mathrm{Y}$, the effect of $\mathrm{X}$ on $\mathrm{M}$, the effect of $\mathrm{M}$ on $\mathrm{Y}$ and the effect of $\mathrm{X}$ on $\mathrm{Y}$ controlled for $\mathrm{M}$, and these four steps needed to be significant and satisfied [15]. In addition, to examine the role of covariant such as demographic factors and on the relationship between user acceptance and adoption of technology, multivariate analysis of covariance (MANCOVA) was applied. All measurement items were standardized and missing values were replaced by sample means to examine validity, reliability, and statistical power and the existing relationships. The impacts of each factor were represented by the path coefficients and corresponding levels of significance. $\mathrm{P}$ value $<0.05$ was considered significant in the study.

\section{RESULTS}

The demographic characteristics of participants $(n=841)$ who responded to the study were as follows: From the present findings it was observed that majority of the students were from Department of communication (36.6\%) and age group with < 20 years $(95.6 \%)$, male $(65.2 \%)$ and second year $(35.8 \%)$. Thus it is clear that the study has generated responses from varied range of respondents adequately representing the diversity of the total population of students in the institutions. The students were familiar with the digital environment than the traditional print media. The findings of the present study in relation to students learning style namely Dependent, Competitive, Independent, Collaborative, Participant and Avoidant were identified as the major key factors for students learning style.

Reliability and validity tests were conducted on constructs with multivariate measures. Cronbach's reliability was applied to measure the internal consistency of these multivariate scales [27]. The reliability of the factors of theoretical model ranges from $0.624-0.769$. Thus, testing the instrument is highly applicable to present sample in the study. The results (Table 1) show that the Cronbach's alpha for all dimensions is greater than 0.7 , which indicates higher level of reliability for the survey instrument in the study [12]. Further the reliability of Students learning style had six factors such as Dependent, Competitive, Independent, Collaborative, Participant and Avoidant and their Cronbach's alpha ranged from $0.512-0.87$.

Table 2 presents the regression analysis and shows a significant association between Performance expectancy $(\beta=0.821, \mathrm{t}=25.35, \mathrm{p}<0.001)$, Effort expectancy $(\beta=0.795$, $\mathrm{t}=8.878, \quad \mathrm{p}<0.001)$, Social influence $(\beta=0.606, \mathrm{t}=13.366$, $\mathrm{p}<0.001)$ and Facilitating conditions $(\beta=0.648, \mathrm{t}=0.050$, $\mathrm{p}<0.001)$ significantly predicted adoption of blended learning at CAS. The overall dimensions of User Acceptance (i.e., Performance expectancy, Effort expectancy, Social influence and Facilitating conditions) explains 48.6 percent variation on behavioral intention. To examine whether the relationship between user acceptance of technology and blended learning adoption is mediated by learning style of students, the Sobel test was applied. The finding of mediation analysis revealed that independent learning style of students mediate the relationship between Performance expectancy $(z=-1.637$, $p<0.001)$ and behavioural intention (data not shown).

Table 3 presents moderating role of demographic factors with the relationship between user acceptance and blended learning adoption was analysed using ANCOVA. User acceptance has significant impact on behavioural intention using moderating variable such as age $(\mathrm{F}=177.244, \mathrm{p}<0.01)$, gender $(\mathrm{F}=31.748$, $\mathrm{p}<0.01)$, computer experience $(\mathrm{F}=27.276, \mathrm{p}<0.01)$ and combination of gender, age and computer experience $(\mathrm{F}=37.674, \mathrm{p}<0.01)$ 


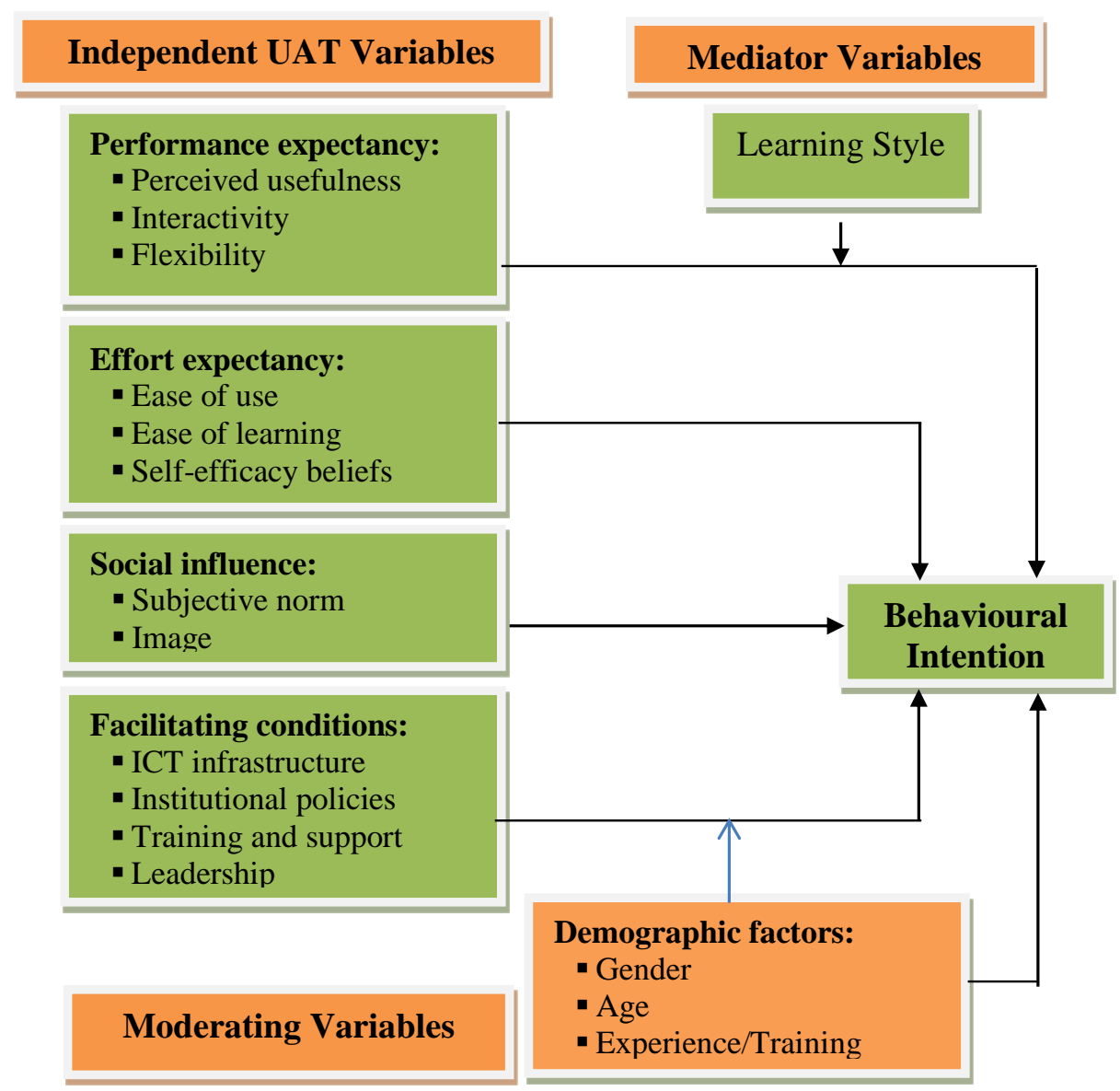

Fig 1: Blended Learning Acceptance Model (BLAM), (A model based on present findings)

\section{DISCUSSION AND CONCLUSION}

The present study identified the factors affecting the adoption of blended learning at CAS in Oman. The study adopted a unique application of the blended learning adoption in Higher education Institutes (HEI) in Oman environment by combining UTAUT model and ELAM model. Further, the study explained the concept of blended learning from the viewpoint of students and assessed learning practices implemented and the approaches for the current trends which have evolved over the years. In Oman, there was establishment of various new colleges and universities across the whole regions; hence it is a necessary to improve more free higher education which will be useful to more number of citizens. Thus, the present study attempted to deliver new model blended learning adoption in the Oman Higher Education.

Thus, in the current research behavioural intention in relation to the user acceptance was included in the blended learning adoption [14]. The finding of the present study revealed that factors such as Dependent, Competitive, Independent, Collaborative, Participant and Avoidant affect the adoption of blended learning among students. Earlier studies found that the effectiveness of blended learning activities as compared to traditional settings in pursuance of high level of learning [25]. Thus, the blended learning can develop the high level of motivation, utility and satisfaction among students which in turn generate positive attitudes towards learning [21]. These approaches help the decision makers of higher education to identify issues with respect to quality of academic program, access of students as well as curriculum delivery [29] \& [33].
In the current study, the students learning style such as Competitive, Independent, Collaborative, Participant and Avoidant does not significantly influenced the behavioural intention (blended learning adoption) among students. The finding was is in line with the earlier studies which have revealed that a negative attitude towards technology and computers has been correspond with the refusal to accept to the new technology [23] \& [38], at the same time the other research findings have identified that eLearning attitudes have no significant impact on inexperienced users performances of eLearning [23].

The learning style of students, significantly mediated the relationship between the behavioural intention (blended learning) on competitive and facilitators. Age, gender, and experience were hypothesized to moderate the effects of user acceptance and behaviour intention. Further, the user acceptance of technology and blended learning adoption is mediated by the independent learning style especially with performance expectancy. However, previous studies have suggested that gender had no moderating effects and age has intervened mainly with performance expectancy and facilitating conditions [5] \& [40]. Thus, the adopted conceptual framework in the study can be adapted and implemented in CAS Oman.

The results confirm several of the relationships in the UTAUT model as proposed by [40], but the UTAUT model is contradicted in two ways: (1) The Facilitating conditions significantly affect behavioural intention even when the effects of Performance expectancy and Effort expectancy on 
behavioural intention are included. (2) Effort expectancy does not have a significant impact on behavioural intention.

\section{CONCLUSION}

The present study has successfully explored the association between behaviour intention (dependent variable) and user acceptance (independent variable) by using learning style as a mediating variable. This study utilizes both moderator (demographic factors) and mediating variables (student learning style) to identify the impact of user acceptance on behavioural intention (blended learning adoption). In blended learning environment, learning satisfaction is considered as major element and this can be achieved by providing appropriate facility. Student satisfaction was found to be significantly influenced by the factors like perceived usefulness, interactivity and flexibility ease of learning and efficiency of students, subjective norm and image of students, institutional policies, leadership of students and training and technical support in blended learning adoption. From the findings of the study, it can be concluded that BLAM model is valid, and it has significant effect on blended learning adoption. In learning style, performance expectancy is considered as important factor for blended learning adoption among student. Oman is in initial stage in developing adoption of blended learning. This BLAM model would assist them to implement blended learning adoption at CAS, Oman by considering performance expectancy as essential factor.

\section{RECOMMENDATION}

The suggested BLAM model is valid; however future research has to focus on the development of more design on the blended learning adoption. Future research can extend model by including actual usage to foster the concept of blended learning adoption. Further blended learning adoption has to be implemented in higher education institution by structuring the suitable framework, since it helps to overcome the issues that are faced by higher education institution in Oman. Blended learning provides benefit to the students by facilitating learning which in turn enhances the student access and flexibility as well as organizational cost-effectiveness.

No previous studies have been conducted on Blended learning adoption using UTAUT model in Oman. Therefore this study helps to implement blended learning adoption at CAS, Oman. However, this study has limitation such as study has chosen convenience sampling technique, therefore it lack representative. The study has adopted cross sectional design. Therefore future has to focus on longitudinal study to follow up the students on usage of blended learning. Finally this study has conducted only for leaning style of students, thus future study has to include teaching style of teachers.

\section{REFERENCES}

[1] Adkins, S., 2011. We Put Research into Practice. Online Research paper, http://www.ambientinsight.com/Resources/Documents/A mbientInsight_2007-

2012_Corporate_LearningServices_Market_ExecOvervi ew.pdf

[2] Akour, H., 2009. Determinants Of Mobile Learning Acceptance: An Empirical nvestigation In Higher Education. Research paper, Oklahoma State University.

[3] Alebaikan, R. 2010. Perceptions of blended learning in Saudi universities. Doctor of Philosophy Thesis, University of Exeter.
[4] Allen, I. E. and Seaman, J. 2010. Learning on demand: Online education in the United States, 2009. Newburyport, MA: The Sloan Consortium. http://sloanconsortium.org/publications/survey/learning on_demand_sr2010.

[5] Anderson, J. E., Schwager, P. and Kerns, R. 2006. The drivers of acceptance of tablet PCs by faculty in a college of business. Journal of Information Systems Education, 17 (4), 429-440.

[6] Bandyopadhyay, K. and Fraccastoro, K. 2007. The effect of culture on user acceptance of information technology. Communications of the Association for Information Systems, 19 (1), 522-543.

[7] Bigne, E., Ruiz, C. and Sanz, S. 2005. The Impact Of Internet User Shopping Patterns and Demographics on Consumer Mobile Buying Behaviour. Journal of Electronic Commerce Research, 6(3): 193-210.

[8] Bostrom, R. P., Olfman, L. and SeinM. K. 1990. The Importance of Learning Style in End-User Training. MIS Quarterly, 101-119.

[9] Cavus, N., Bicen, H. and Akeil, U. 2008. The opinions of information technology students on using mobile learning. In the proceedings of 2008 International Conferences on Educational Sciences, 228-325.

[10] Chan, D. 2011. A comparison of traditional and blended learning in introductory principles of accounting course. American Journal of Business Education, 4 (9), 1-10.

[11] Cohere. 2011. Innovative practices, Research project, Cohere report on blended learning. Human Resources and Skills Development, Canada.

[12] Cuieford, J. P. 1965. Fundamental Statistics in Psychology and Education (4th ed.). McGraw-Hill, New York.

[13] Dillman, D. A. 2000. Procedures for conducting government-sponsored establishment surveys: comparisons of the Total design Method (TDM), A Trational Cost-Compensation Model, and Tailored Design, 343-372.

[14] Farida Umrani-Khan and Sridhar iyer. ELAM: A Model for Acceptance and use of e-learning by Teachers and Students. International conference on e-learning, Toronto, Canada, July, 2009.

[15] Fearson, C., Starr, S. and McLaughlin, H. 2011. Value of blended learning in university and the workplace: Some experiences of university students. Industrial and Commercial Training, 43 (7), 446-450. http://dx.doi.org/10.1108/00197851111171872.

[16] Fritz, M.S., \& Mackinnon, D.P.2007. Required sample size to detect the mediated effect. Psychological Sxience, 18(3), 233-9. doi: 10.11 11/j.1467-9280.2007.01882.x

[17] Graham, C. 2006. Blended learning systems: definition, current trends, and future directions. In: Bonk, C. and Graham, C. (Eds.), Handbook of blended learning: global perspectives, local designs. San Francisco, CA: Pfeiffer.

[18] IBM Corp. Released 2012, version 21.0, Armonk, NY: IBM Corp, http://www01.ibm.com/support/docview.wss?uid=swg27024941 
[19] Jones, S., Johnson-Yale, C., Millermaier, S. and Perez, F. S. 2008. Academic work, the Internet and US college students. Internet and Higher Education, 11, 165-177.

[20] Li, J.P. and R. Kishore, 2006. How Robust is the UTAUT Instrument? A multigroup Invariance Analysis in the Context of Acceptance and Use of Online Community Weblog Systems. In the Proceedings of the 2006 ACM SIGMIS CPR Conference, 183-189.

[21] Lopez-Perez, V.M., Perez-Lopez, C.M. and RodriguezAriza, L. 2011. Blended learning in higher education: Students' perceptions and their relation to outcomes. Computers and Education, 56(3), 818-826. http://dx.doi.org/10.1016/j.compedu.2010.10.023

[22] Lu, J., Yu, C. S. and Liu, C. 2009. Mobile data service demographics in urban China. Journal of Computer Information Systems, 50(2), 117-126.

[23] Lynch, T. G., Steele, D. J., Johnson Palensky, J. E., Lacy, N. L. and Duffy, S. W. 2001. Learning preferences, computer attitudes, and test performance with computeraided instruction. American Journal of Surgery, 181, 368-371.

[24] Lynch, T. G., Woelfl, N. N., Steele, D. J. and Hanssen, C. S. (1998), 'Learning style influences student examination performance. American Journal of Surgery, $176,62-66$.

[25] McCray, G. E. 2000. The hybrid course: Merging on-line instruction and the traditional classroom. Information Technology and Management, 1, 307-327.

[26] Norberg, A., Dziuban, C. D. and Moskal, P. D. 2011. A time-based blended learning model. On the Horizon, 19, 207-216. http://www.emeraldinsight.com/loi/oth

[27] Nunnally, T. 1978. Psychometric Theory, New York: McGraw Hill.

[28] Patton, M. Q. 1990. Qualitative evaluation and research methods. $2^{\text {nd }}$ ed. Newbury Park, CA: Sage

[29] Picciano, A. G. 2009. Blending with purpose: the multimodal model. Journal of the ResearchCenter for Educational Technology, 5(1), 4-14.

[30] Roberts, G.R., 2005. Technology and Learning Expectations of the Net Generation. On Line Research Paper, http://www.educause.edu/ research-andpublications/books/educating-net-generation/technologyand-learning-expectations-net-generation
[31] Ross, B. and Gage, K. 2006. Global perspectives on blending learning: Insight from WebCT and our customers in higher education. In Bonk, C. J. and Graham, C. R. (Eds.), Handbook of blended learning: Global perspectives, local designs, San Francisco, CA: Pfeiffer Publishing, 155- 168.

[32] Sharples, M. 2005. Learning as conversation: Transforming Education in the Mobileage. Educase Online,

www.eee.bham.ac.uk/sharplem/Papers/Theory\%20of $\% 2$ 0learning\%20Budapest.pdf

[33] Stacey, E. and Gerbic, P. 2009. Introduction to blended learning practices. In: Stacey, E. \& Gerbic, P. (Eds.), Effective blended learning practices: evidence-based in perspectives in ICT-facilitated education, Hershey, PA: IGI Global.

[34] Su, B., Bonk, C.J., Magjuka, R. J., Liu, X. and Lee, S. 2005. The importance of interaction in web-based education: A program-level case study of online MBA courses. J. Interactive Online Learning, 4, 1-18.

[35] Tan, Z. and Ouyang, W. 2004. Diffusion and Impacts of the Internet and E-Commerce in China. Electronic Markets, 14(1), 25-35.

[36] Triandis, H.C., 1995. Individualism and collectivism, Boulder, CO: Westview.

[37] Umrani-Khan, F. and Iyer, S. 2009. ELAM: A model for acceptance and use of e-learning by teachers and students. Proceedings of the 4th International Conference on E-Learning. University of Toronto, Canada, 1-25.

[38] Van Dover, L. and Boblin, S. 1991. Student nurse computer experience and preferences for learning. Computers in Nursing, 9, 75-79.

[39] Venkatesh, V., Morris, M. G., Davis, G. B. and Davis, F. D. 2003. User acceptance of information technology: toward a unified view. MIS Quarterly, 27 (3), 425-478.

[40] Venkatesh, V., Morris, M. G., Davis, G. B., and Davis, F. D. 2003. User acceptance of information technology: Toward a unified view. MIS Quarterly, 27(3), 425-478.

[41] Yuen, H.K.A. and Ma, W.W.K. 2008 Exploring Teacher Acceptance of e-learning Technology. Asia-Pacific Journal of Teacher Education, 36(3), 229-243.

Appendix

Table 1. Reliability of the factors

\begin{tabular}{|l|c|c|}
\hline Factors & No. of items & Cronbach's Alpha \\
\hline \multicolumn{2}{|c|}{ I Performance Expectancy (PE) } \\
\hline Perceived Usefulness & 7 & 0.762 \\
\hline Interactivity & 3 & 0.512 \\
\hline Flexibility & 4 & 0.639 \\
\hline
\end{tabular}




\begin{tabular}{|c|c|c|}
\hline \multicolumn{3}{|c|}{ II Effort Expectancy (EE) } \\
\hline Ease of learning & 3 & 0.731 \\
\hline Ease of use & 5 & 0.769 \\
\hline Self-efficiency & 4 & 0.714 \\
\hline \multicolumn{3}{|c|}{ III Social Influence (SI) } \\
\hline Subjective Norm & 3 & 0.652 \\
\hline Image & 3 & 0.707 \\
\hline \multicolumn{3}{|c|}{ IV Facilitating Conditions (FC) } \\
\hline ICT Infrastructure & 3 & 0.719 \\
\hline Institutional Policies & 3 & 0.697 \\
\hline Training and Technical Support & 3 & 0.624 \\
\hline Leadership & 3 & 0.644 \\
\hline \multicolumn{3}{|c|}{ V Blended Learning (BL) } \\
\hline Behavioural Intention & 3 & 0.655 \\
\hline \multicolumn{3}{|c|}{ VI Students Learning Style } \\
\hline Dependent & 10 & 0.813 \\
\hline Competitive & 10 & 0.802 \\
\hline Independent & 10 & 0.838 \\
\hline Collaborative & 10 & 0.871 \\
\hline Participant & 10 & 0.822 \\
\hline Avoidant & 10 & 0.821 \\
\hline
\end{tabular}

Table 2. Regression analysis

\begin{tabular}{|l|c|c|c|c|}
\hline User acceptance & Beta & t-value & P-value & Accepted/rejected \\
\hline Perceived usefulness & 0.560 & 17.838 & $<0.001$ & Accepted \\
\hline Effort expectancy & 0.795 & 8.878 & $<0.001$ & Accepted \\
\hline Social influence & 0.606 & 13.366 & $<0.001$ & Accepted \\
\hline Facilitating conditions & 0.648 & 13.096 & $<0.001$ & Accepted \\
\hline
\end{tabular}


Table 3. Association between Behavioural intention and User acceptance technology by Demographic variables

\begin{tabular}{|c|c|c|c|c|c|c|}
\hline \multicolumn{7}{|c|}{ Dependent Variable: Behavioural Intention } \\
\hline Source & $\begin{array}{l}\text { Type III Sum of } \\
\text { Squares }\end{array}$ & df & $\begin{array}{l}\text { Mean } \\
\text { Square }\end{array}$ & $\mathbf{F}$ & Sig. & $\begin{array}{l}\text { Partial Eta } \\
\text { Squared }\end{array}$ \\
\hline Model & 12477.591 & 4 & 3119.398 & 1480.432 & .000 & .876 \\
\hline STPE $x$ STEE $x$ SSI $x$ SFC $x$ stage & 373.467 & 1 & 373.467 & 177.244 & $.000 * *$ & .175 \\
\hline STPE $x$ STEE $x$ SSI $x$ SFC $x$ stgender & 66.896 & 1 & 66.896 & 31.748 & $.000 * *$ & .037 \\
\hline STPE $x$ STEE $x$ SSI $x$ SFC $x$ compexpnew & 57.473 & 1 & 57.473 & 27.276 & $.000 * *$ & .032 \\
\hline $\begin{array}{l}\text { STPE x STEE x SSI x SFC x stgender } x \text { stage } x \\
\text { compexpnew }\end{array}$ & 79.383 & 1 & 79.383 & 37.674 & $.000 * *$ & .043 \\
\hline Error & 1763.631 & 837 & 2.107 & & & \\
\hline Total & 14241.222 & 841 & & & & \\
\hline
\end{tabular}

STPE $=$ Students Performance Expectancy; STEE $=$ Student Effort Expectancy SSI = Student Social Influence SFC $=$ Student Facilitating Condition; stgender $=$ Gender stage=Age educt $=$ Education compexpnew $=$ Computer experience 